\title{
Primary repair of ear laceration with wedge resection
}

\author{
Bhupinder Singla, Inderjit Chawla, Prasant Gautam, Anupam Goyal, Jalaj Rathi \\ Department of General Surgery, Rajindra Hospital, Patiala 147001, Punjab, India.
}

Address for correspondence: Dr. Bhupinder Singla, Department of General Surgery, Government Medical College, Samana Road, Patiala 147001, Punjab, India. E-mail: akash22singla@yahoo.com

\begin{abstract}
Although major contributions have been made in the field of reconstructive surgery, reconstructive surgery of the auricle is a daunting prospect even for the most experienced surgeons. Here, we present a case who presented to us in the emergency surgical ward with a history of an accidental laceration of right ear. Primary repair of the ear laceration after wedge resection of the avulsed part was done. The cosmesis achieved by this technique is discussed.
\end{abstract}

Key words:

Ear laceration, primary repair, wedge resection

\section{INTRODUCTION}

Ear laceration is one of the common auricular injuries among traumatic injuries. The type of reconstruction selected for the lacerated ear depends on the size of the defect and the amount of cosmesis expected by the procedure. It ranges from the wedge resection and direct advancement to reconstruction with chondrocutaneous flaps. This report presents a case of auricular laceration in 18-year-old boy who was managed by primary repair of the ear after wedge resection. A good cosmetic result was achieved.

\section{CASE REPORT}

The 18-year-old boy presented in our emergency surgery department with a history of an accident. On examination, the boy was conscious with laceration of right ear involving the skin and cartilage with tissue loss [Figure 1]. The ear was washed thoroughly to remove any foreign body. The patient was taken to the emergency operation theatre for repair with local anesthesia with $1 \%$ lidocaine

\begin{tabular}{|l|l|}
\multicolumn{2}{|c|}{ Access this article online } \\
\hline Quick Response Code: & Website: \\
\hline & www.parjournal.net \\
\cline { 2 - 2 } & \\
\hline
\end{tabular}

with epinephrine 1:100,000. A wedge excision of the damaged part of the ear was done. The wound was then closed in a layered fashion re-approximating the cartilage with 30 catgut and re-approximating the epidermis with a running top suture of 5-0 prolene [Figure 2]. With regular dressings and antiseptic precautions, wound healed well with no residual necrosis [Figure 3].

\section{DISCUSSION}

Lacerations and abrasions are among the most common auricular injuries. The golden rule in such cases after adequate local anesthesia is to balance minimal debridement with maximal tissue preservation. ${ }^{[1]}$

Reconstruction of composite (skin and cartilage) defects of the ear may be broadly classified into two groups: wedge resection and direct advancement, and reconstruction with chondrocutaneous flaps. Small helical defects (often up to $2 \mathrm{~cm}$ ) involving the helix and antihelix can be repaired with a wedge excision. ${ }^{[2]}$ The apex of the wedge may extend into the conchal bowl. Wedge resections and helical advancements shorten vertical ear height but maintain the relative proportions. ${ }^{[3]}$

For defects larger but $<25 \%$ of the auricle, a star excision, or anterior composite Burows triangle excision, can redistribute tension throughout the ear and avoid cupping.

Various chondrocutaneous reconstruction methods have been described for defects up to one-third of the auricle. Large composite defects require a new structural support followed by a vascularized skin flap. 


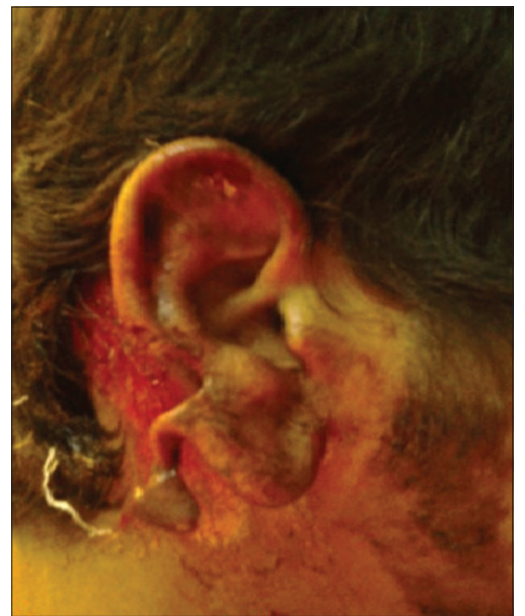

Figure 1: Ear laceration on helix extending anteriorly

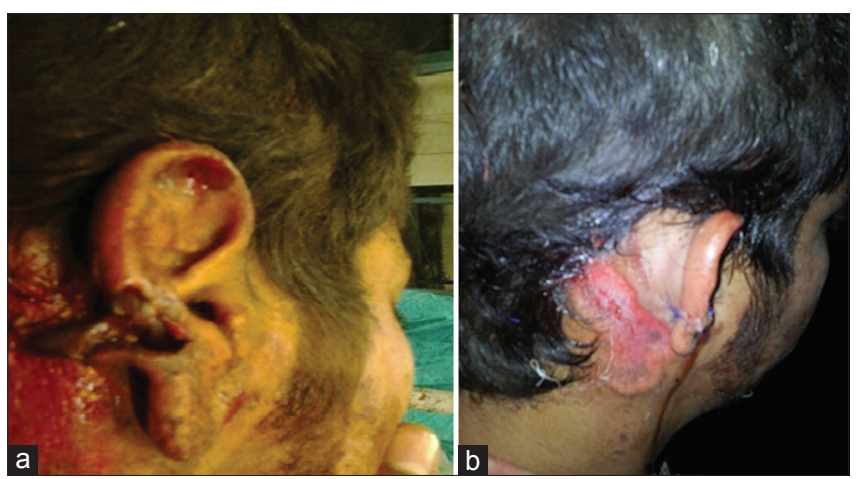

Figure 2: Stitching with prolene 5-0. (a) During stitching, (b) after stitching

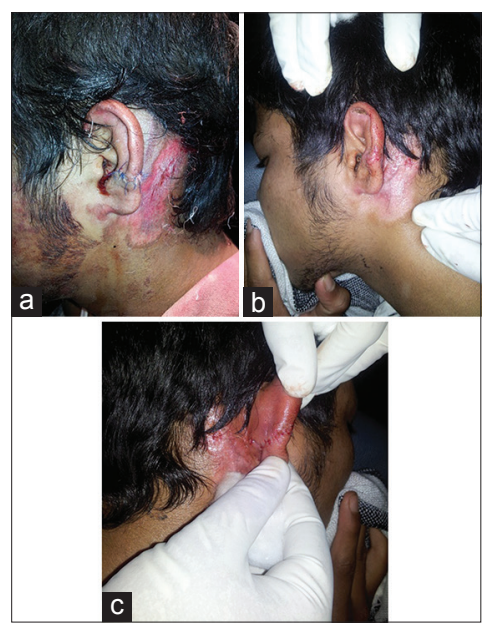

Figure 3: Postoperative follow-up. (a) At day 7, (b) lateral view, (c) posterior view

Primary repair of the ear after wedge resection is a standard procedure followed for auricle injuries. When the helical rim is affected, a vertical mattress suture should be placed initially at the rim to evert the wound edges and level the wound. ${ }^{[4]}$ It is also important to stress the important role of dressing and good wound care in order to obtain a better cosmetic outcome. ${ }^{[1,5]}$ For small composite defects of helix and antihelix, a wedge or star-shaped excision technique is a preferable option. ${ }^{[5]}$ It consists of a full-thickness excision of skin and cartilage with the apex pointing to the anterior surface of the ear and extending to the conchal area. When designing the wedge, it is important to define an apex angle smaller than $30^{\circ} .{ }^{[6]}$ The resulting wound is then closed primarily in layers, with the cartilage secured by long lasting sutures. ${ }^{[5]}$ It is helpful, when possible, to use an offset skin closure around the rim. To decrease the risk of rim notching, the skin should not be approximated and secured over the cartilage space. ${ }^{[7]}$ Usually, the ear is shortened slightly while maintaining the premorbid contour. ${ }^{[7]}$ The advantages of wedge resection are: a one-stage operation, simple and fast dissection, and minimal resultant scar.

However, the limitation of this technique is that it can be applied only for small defects of the helical rim and neighboring structures. The wedge should be located in the superior or posterior third to avoid deformity of the ear. If the defect is larger or located near the anterior helix, wedge resection cannot be used without severe deformity of the ear. ${ }^{[2]}$

Our technique is quite similar to the one described by Ferri ${ }^{[8]}$ and Schonauer et al., ${ }^{[9]}$ in terms of excising a wedge triangle but lacks the second incision at the helical root level. Aesthetic results of the reconstructed ear are maximized by balancing forces on the frontal and sagittal planes. Furthermore, anatomical landmarks and relative proportions are preserved.

This report shows that good cosmetic results can be obtained by managing the ear avulsion with standard procedure of wedge resection followed by primary repair.

\section{REFERENCES}

I. Havlik RJ, Sadove AM. Repositioning the malpositioned ear. Oper Tech Plast Reconstr Surg 1997;4:141-5.

2. Elsahy NI. Reconstruction of the ear after skin and cartilage loss. Clin Plast Surg 2002;29:201-12, vi.

3. Reddy LV,Zide MF. Reconstruction of skin cancer defects of the auricle.J Oral Maxillofac Surg 2004;62:1457-7I.

4. Elsahy NI.Acquired ear defects. Clin Plast Surg 2002;29:I 75-86, v-vi.

5. Park SS, Hood RJ. Auricular reconstruction. Otolaryngol Clin North Am 200I;34:7I3-38, v-vi.

6. Pham TV, Early SV, Park SS. Surgery of the auricle. Facial Plast Surg 2003; 19:53-74.

7. Calhoun $\mathrm{KH}$, Chase SP. Reconstruction of the auricle. Facial Plast Surg Clin North Am 2005; I 3:23 I-4I, vi.

8. Ferri M. Treatment of partial losses of the helix. Plast Reconstr Surg 1998; 101:2011-2

9. Schonauer F, Campa D, Monaco A, Molea G. Staggered wedge technique for ear reconstruction. Plast Reconstr Surg 2010;125:e203-4.

How to cite this article: Singla B, Chawla I, Gautam P, Goyal A, Rathi J. Primary repair of ear laceration with wedge resection. Plast Aesthet Res 2015;2:38-9.

Source of Support: Nil, Conflict of Interest: None declared.

Received: 21-05-2014; Accepted: 10-10-2014 